\title{
BOOK-BINDING AS A SCHOOL CRAFT
}

\author{
GERTRUDE STILES \\ School of Education
}

There has been, within the past two or three years, a very keen interest in the subject of book-binding as hand-work in schools. Wood, pottery, metal, and the textiles, including all forms of weaving, having passed their probationary stage, seem now established as an important and necessary factor in the course of study. The crafts themselves have decided their own limitation and boundaries. The instructors in charge of the handwork have not been slow to recognize these imposed boundaries; to see the possibilities lying within the confines. Therefore, the proper relation of the crafts to what might be called the regular school work has been the more readily established. Instructors in the crafts have been recruited from the ranks of the professional teacher, or have studied well the teaching questions and have a knowledge of the child, what he wants to do, what he can do, what is best for him to do, and what line of work will best promote his development.

So the three-the child's ability, the crafts' limitation, and the teacher's knowledge-have placed the hand-work in right relation to the more fully established studies.

The hand-work is universally recognized. Book-binding as one of the forms of hand-work has yet to fulfil its present alluring claims and promises.

Too well do we know the great wave of enthusiasm which sweeps us on in the study of any new subject. We neglect details and resist every suggested obstacle-possibilities are almost limitless. After this first burst, however, we are thrown back on the dry sands of limitation-it is not what we had thought-it is useless, barren, why have wasted the time? To do the best within these limitations-to discard, to select, and to arrange-is the problem. 
I view the subject from the standpoint of a craftsman, having had but limited experience and small insight, I fear, into the realm of its educational possibilities. And what I say will be said tentatively (for we cannot as yet arrive at many conclusions) and with a suggestion or two of what it seems to me might be done, and, finally, of a few of the exhibited results which have so far been obtained.

The present chaotic state of book-binding in schools comes, I think, from a lack of interest on the part of the craftsmen. No one as yet has set himself to a study of its educational features, to a study of its simplification to elemental form, or even to any systematic outline of book-construction. Those who have undertaken its teaching have not, for various and obvious reasons, been able to master sufficient of the craft to reduce it to its simplest elements, or even to see fully the great possibilities within its limitations.

As an art, practiced by but few, it is most arduous, requiring skill beyond the average, practice of years (Cobden Sanderson says it takes ten years to make a book-binder), an exquisite judgment involving both artistic and literary taste, a combination of manual dexterity, of poetic and artistic feeling, of enthusiasm which shall carry one through many a Slough of Despond. It seems so far beyond the child's comprehension: why bring it from this high estate, where it has lived for centuries, loved and honored by the world's potentates, to place it in our common schools? How the patron saint of book-binding-Grolier, maybe-must groan in spirit at the atrocities committed in his name!

Is it so surprising, then, that a craftsman guards so jealously his craft? But the traditions of a craft need not be destroyedby a judicious selection of certain forms which may be useful to us-any more than the beauty of any opera is destroyed by the rendering of a detached portion. And these portions prove stepping-stones to a bigger understanding of the whole.

Book-binding has been carried on with success in normal and high schools. Equipment and supplies, necessary working space, and students have all been ready at hand, proving again the keen 
interest in the work. In the elemenary schools, however, it has been confined to the making of portfolios and the small wordbooks of the earlier grades. These, both, are important steps in book-construction, and, with proper attention at their making, could be made the first movement toward a correct sequence of the various problems which book-binding involves. The portfolio is an exact duplicate of a case-binding minus the book. The word-books, tied with thread through the fold of the section, are of the simplest form of pamphlet binding, and often involve, if made of large sheets of folded paper, an immediate example of folio or quarto, as the paper may happen to be ; if made of single sheets, punched with holes and tied, the book is an embryo photograph album. They are identical in construction, but somewhere the connection is lost; this little thread of instruction is either tied right there in a hard knot and forgotten, or it is allowed to drag through a few intermediate stages, trailing along, blown here and there, a bit of waste, unnoticed, unattached, until, if it does reach the book-binding classes, it is so worn and frayed, so shabby and tangled, as to be absolutely useless.

Book-binding seems forced to spell itself with a capital B; to stand apart, fenced about, just a little mysterious and unnatural, and all the time it is wishing to be spelt with a little $b$; to be allowed to take its upward shoot naturally, to grow a little each year, and to be right.

One seventh-grade boy retained a thread of what he had gained in the earlier years, when, in making a book for kodak pictures, he proclaimed it, rather contemptuously, a "kindergarten stunt." But as he worked, the problem lost its infantile character, and the boy after having done it all himself seemed rather proud of the result.

Book-binding touches closely the general cause of study at many points-as hand-work, art-work, and as a literary and historic study. As hand-work, the immediate needs of the children or the school offer a wide range in subject-matter, and as sufficient training is gained these needs can be supplied. Such work must be simple-not involving too much time-for should it be a book in constant use, it must be put into its cover quickly. 
The question of utility is a large one in supplying these demands. Often, a small book in constant use is put in a casebinding without resewing, as sewing would place the book out of service for too long a time. The beginning French lessons were put into a simple tied cover, allowing more sheets to be added as the French lessons progressed. This is almost the only way we have of binding single sheets. Commercial houses do them differently, to be sure.

In the constructive work, there is a wide field in various forms of folios, with or without pockets. The child can make what he most needs in this line, working it out in size, shape, and style to suit himself. There are various related problems, such as the making of pocket-books, card-cases, stamp-books, writing folios-the list is endless-coming often under the head of "leather work," which should be included here, brought into line and recognized as a phase of book-construction.

As to books themselves, unless a blank book, the binder is more restricted. It is not purely creative, but a thing already existing about which he must build, using the book itself as an integral part of that construction. Tradition too binds him, for books can only be made in certain correct ways; yet, even in this, he can be given the initiative in choosing one of the few ways in which to do it. These ways must be taught and their various adaptabilities brought out as clearly as possible. In the earlier grades the boards should be cut for the children, but the practice in pasting and cutting and calculating of paper for covers can be gained. Later, when the child begins to cut boards for himself a distinct falling off in the appearance of the finished result will be unavoidable. A good-sized photographic cutter will be necessary. The use of the plough and press I think a little complicated for even the eighth grade, yet we have used it there. The children are invariably delighted with its use, and a few seem to understand it fairly well, but the many adjustments necessary, such as perfect pressure, cut against, level running of the knife, even screwing up of the pins, to say nothing of the sharpness of the knife, are so many that a child is apt to forget one or more in his eagerness. This eagerness is difficult at best to manage- 
they see one point and dive. In this connection of helping the child to plan, and to consider the many points necessary a working formula could be made. The child could write out carefully, with the teacher's help, the processes involved in the making of his particular book-all the frequent pressings noted, all details recorded, in the order in which they should be followed, the color and kind of leather and paper he is to use, and keep this as a reference.

Pamphlet bindings are of various forms of making, and are a good problem for the first sewing-many of them with two kettle stitches, some larger books with three. Those going into covers of paper later, the same sewing can be combined with an advance in the manner of the attachment of the boards, using a different arrangement of leather or cloth, with the paper. Sewing on tapes comes next, and can be carried out in case-binding or in one or more forms of library binding. If in a library binding, we always back the book and attach the boards by either lacing the tapes through, or by using a split board. We have not tried with the children, and it would seem too advanced a form, the regular flexible sewing-on cords. Nor have we used the condemned sunken cord. The tapes seem to answer all purposes.

The children like the work and at the close of the hour over half the class will remain for "just a little more." Sometimes, to be sure, a child will complain of the care required, and one girl, after receiving criticism, said: "Have I got to do that over again? I just hate this. I wouldn't have come into the class, only I wanted the things we make." A frivolous remark, and from a girl not commended for serious work in any department, yet it proclaims a sentiment, a desire for some of the "things," and a wish to preserve work done in other lines.

Second, as art-work: In this, it extends its boundaries; for what cannot be lavished on the book! It first will join with the printing in producing a good "inside." This "inside," the real book, may have illustrations, fancy borders, head and tail pieces, initials, illuminations, what not? Passing, then, forward to the binding stage, it can have suitable and elaborate end-papers, 
designed and hand colored, they may be stenciled or done with wood blocks; the covers can also be stenciled or specially designed, decorative lettering becomes a feature in the titling. Covers could be made of cloth and embroidered in some simple outline stitch, or these, in turn, stenciled or blocked. So far, we have attempted no decoration, beyond a line or two following the outline of the tapes through the leather, across the back, based upon structural lines alone-the most legitimate form of decoration. We have tried to gain good color effects in our choice of leathers and papers. The various Japanese papers have been of great service.

We have made a decorative feature of the sewing by using bright-colored thread over leather or tape, and not covering this, but covering only the boards, allowing this to appear. The art and manual training can give each the hand of helpfulness in working out some delightful examples in this art.

Third, in correlation with history and literature. The study of the history of book-binding, of the glorious record of its faithful followers during the monastic period; its vital connection with the history of printing; the effect printing had upon its career; its connection with the goldsmith's art; the jewels used for its further enriching; the story of the Book of Kells; the great names of famous book-lovers of the past; the story of the first public libraries; the history of papyrus and parchment; study even the derivation of our words "volume" and "codex;" the whole history of the primer and the New England primer in particular, of which that charming reproduction was made a few years ago; the hornbook which they have duplicated in wood and isinglass; all this opens a field of unusual interest and beauty. Nothing more exquisite has been written than Friar Jerome's Beautiful Book. Read a bit of Eugene Field's Love Affairs of a Bibliomaniac, quaint and humorous. A few chapters in Brander Matthews'Book-bindings, Old and New, will stir the interest afresh. One chapter in it speaks only of cloth-covered, commercially bound books. What an interest can be aroused to a consideration of the art, the labor and thought expended on this most intimate object of our everyday use! In the smallest town 
interesting books are to be found. Why could these not be brought together by a class and investigated? Old books are intensely interesting in their making, and inquiring glances down their backs, to their sides, their heads and joints-all homely technical terms-will delight and reward a class who know something of how books are made. Surely all this is more or less cultural-an attempt to secure that intelligent interest in the pursuits and the products of others. Surely this cannot fail to bring about that more serious regard for books-the lack of which is sometimes bewailed; that love for books-without which no man is truly great. 